\title{
PENGARUH PROFESIONALISME DAN DISIPLIN KERJA GURU TERHADAP PENINGKATAN MUTU PENDIDIKAN DI SEKOLAH DASAR
}

\author{
Ratna Dewi \\ Sekolah Tinggi Agama Islam ALHIKMAH, Jakarta, Indonesia \\ olaabeel@gmail.com \\ Sita Husnul Khotimah \\ Sekolah Tinggi Agama Islam ALHIKMAH, Jakarta, Indonesia \\ sita_kh81@yahoo.com
}

\begin{abstract}
The purpose of this study was to determine and analyze the effect of professionalism, teacher work discipline and their interactions in improving the quality of education at SDN 04 Cipedak and MIN 08 Jagakarsa, South Jakarta. The results showed, 1) there is a significant influence between teacher professionalism on the quality of education, teacher professionalism has an effect of $78.5 \%$ on the quality of education and the remaining $21.5 \%$ is caused by other factors that the authors do not observe. 2) teacher work discipline on the quality of education has an effect of $83.5 \%$ and the remaining $16.5 \%$ is caused by other factors that are notobserved by the authors. 3) the results of the joint analysis between the professionalism and discipline of teacher work on improving the quality of education are positive and the effect is very strong, this is indicated by the $R$ value of 0.894 and the $R$ square value of 0.799 or $79.9 \%$. Based on the results of this study, what the principal must do is to strive to improve human resources, especially teachers as human educators to be more competent in their profession by
\end{abstract}


providing opportunities to participate in various trainings both held by the school or from outside the school.

Keywords: : Professionalism; Work Discipline; Quality of Education

\begin{abstract}
Abstrak
Tujuan dari penelitian ini untuk mengetahui dan menganalisis pengaruh profesionalisme, disiplin kerja guru serta interaksi keduanya dalam meningkatkan mutu pendidikan di SDN 04 Cipedak dan MIN 08 Jagakarsa, Jakarta Selatan. Metode yang digunakan adalah deskriptip dengan pendekatan kuantitatif, sedangkan teknik analisa data menggunakan analisis regresi ganda. Sampel dalam penelitian ini adalah 15 orang guru di SDN 04 Cipedak dan 15 orang guru di MIN 08 Jagakarsa. Hasil penelitian menunjukkan, 1) terdapat pengaruh signifikan antara profesionalisme guru terhadap mutu pendidikan, profesionalisme guru mempunyai pengaruh sebesar 78,5\% terhadap mutu pendidikan dan sisanya 21,5\% disebabkan oleh factor lain yang tidak diamati penulis. 2) disiplin kerja guru terhadap mutu pendidikan mempunyai pengaruh sebesar 83,5\% dan sisanya sebesar 16,5\% disebabkan oleh faktor-faktor lain yang tidak diamati penulis. 3) hasil analisa secara bersama-sama antara profesionalisme dan disiplin kerja guru terhadap peningkatan mutu pendidikan bernilai positif dan pengaruhnya sangat kuat, hal ini ditunjukkan oleh nilai $\mathrm{R}$ sebesar 0,894 dan nilai $\mathrm{R}$ square 0,799 atau 79,9\%. Berdasarkan hasil penelitian tersebut, hal yang harus dilakukan kepala sekolah adalah mengupayakan peningkatan sumberdaya manusia khususnya guru selaku insan pendidik agar lebih kompeten dalam profesinya dengan memberikan kesempatan untuk mengikuti berbagai pelatihan baik yang diadakan oleh pihak sekolah atapun dari luar sekolah.
\end{abstract}

Kata Kunci: Profesionalisme; Disiplin Kerja; Mutu Pendidikan 


\section{A. Pendahuluan}

Mendidik, mengajar, membimbing, mengarahkan, melatih, menilai, serta mengevaluasi peserta didik pada jenjang pendidikan formal adalah merupakan tugas utama guru sebagai jabatan profesional (Darmadi, 2015). Tugas utama itu menjadi efektif jika seorang guru memiliki posisi profesionalitas tertentu yang tergambar dari kompetensi, kemahiran, kecakapan atau ketrampilan yang memenuhi standar mutu tertentu. Peraturan Pemerintah (PP) No. 74 Tahun 2008 tentang Guru dan dosen menyatakan, yang disebut guru antara lain; a) Guru itu sendiri, baik guru kelas, guru mata pelajaran, maupun guru bimbingan konseling, b) Guru yang mempunyai tugas tambahan sebagai kepala sekolah, serta c) Guru dengan jabatan pengawas.

Guru profesional memiliki definisi sebagai seorang yang memiliki kompetensi serta keterampialan khusus pada bidang ilmu keguruan, dengan demikian guru bisa melaksanakan tangungjawab beserta fungsinya secara maksimal (Dewi, 2015). Artinya keprofesionalan guru tidak hanya diperoleh dari sekolah formal saja tetapi juga harus mampu da faham terhadap bermacam strategi dalam pembelajaran serta mahir tentang ilmu pedagogik dengan baik.

Tuntutan di atas perlu didukung dengan berbagai upaya untuk meningkatkan kinerja guru yang dilaksanakan dengan cara memberi kompensasi, motivasi, meningkatkan kemampuan, disiplin dan komitmen yang tinggi, serta pemimpin yang baik. Sejalan dengan hasil penelitian (Armani \& Margunani, 2017), yang menyatakan disiplin kerja berpengaruh terhadap kinerja guru mata pelajaran. Satu hal yang juga penting dimiliki oleh seorang guru adalah disiplin terhadap organisasi/lembaga sekolahnya, dalam sebuah organisasi sangat memerlukan kedisiplinan yang tinggi, karena terwujudnya disiplin kerja guru yang tinggi akan mampu mempengaruhi kondisi kerja dan hasil kerja yang profesional. Profesionalisme seorang guru menggambarkan 
mutu pendidikan yang baik, karena guru merupakan faktor utama yang memberikan pelayanan dan pendidikan terbaik kepada peserta didik untuk menjadikan mereka terbaik dan lebih unggul dalam pandangan masyarakat. Sejalan dengan hasil penelitian (Mulatsih et al., 2018), yang menyatakan adanya pengaruh positif profesionalisme guru terhadap Mutu PAUD di Kabupaten Kendal.

Profesionalisme dan kedisiplinan sebagaimana dijelaskan di atas seharusnya ada pada setiap pendidik atau guru. Namun kenyataan di lapangan tidak sedikit guru yang tidak memenuhi kriteria sebagaimana dijelaskan di atas. Pada kalangan guru sering mengabaikan disiplin kerja, hal ini berdasarkan beberapa contoh diantaranya kehadiran guru ke sekolah yang terlambat, pada jam kerja sering tidak ada di sekolah, menunda penyelesaian pekerjaan, pulang lebih awal dari jadwal dan sebagainya. Sejalan dengan hasil pengamatan lapangan (Zubaidah, 2015), yang menyatakan hampir kebanyakan guru menunjukkan sikap disiplin hanya pada waktu pimpinan hadir di sekolah, apabila mengetahui pimpinan tidak hadir mereka merasa leluasa serta cenderung menjadi tidak disiplin. Yang penting bagi guru adalah absensi terisi, hal demikian ini tentunya sangat berpengaruh terhadap prestasi dalam bekerja. Penerapan disiplin sangat berguna untuk kehidupan manusia, oleh karenanya disiplin harus ditanamkan secara berkelanjutan supaya menjadi pembiasaan baik. Pada umumnya guru yang memiliki kedisiplinan yang tinggi, merekalah yang sukses dalam bidang pekerjaannya, kebalikannya guru yang gagal biasanya sering tidak disiplin dalam pekerjaannya. Disiplin adalah sutau proses berlatih dan belajar untuk meningkatkan kemampuan dalam berperilaku, berfikir dan bekerja yang inovatif.

Dari hasil survey awal menunjukkan bahwa guru-guru SDN 04 Cipedak dan MIN 08 Jagakarsa, Jakarta Selatan, masih ada yang belum menunjukkan sikap kreatif, produktif dan mempunyai disiplin kerja yang tinggi pada saat melaksanakan pembelajaran di kelas. Hal ini berdampak para guru kurang memperlihatkan motivasi, disiplin serta kinerja yang maksimal 
dalam menyelesaikan tugasnya, sehingga mempengaruhi mutu lulusan. Sejalan dengan hasil penelitian (Haryati, n.d.), bahwa profesionalisme guru, motivasi dan kedisiplinan kerja memiliki andil dalam mempengaruhi tingkat keberhasilan para guru dalam menjalankan tugas pokok dan fungsionalnya. Oleh karenanya permasalahan tentang profesionalisme dan disiplin kerja guru dalam kontek SDN 04 Cipedak dan MIN 08 Jagakarsa, Jakarta Selatan, menjadi sangatlah penting untuk dikaji bagi lembaga pendidikan tersebut agar mampu meningkatkan mutu pendidikan yang lebih baik.

\section{B. Pembahasan}

\section{Kajian Teori}

\section{a) Profesionalisme Guru}

Menurut Webstar dalam (Kunandar \& Si, 2010) mengartikan profesionalisme sebagai bidang pekerjaan yang akan ditekuni atau didalami oleh seseorang. Sedangkan pekerjaan tertentu dengan syarat ilmu dan keahlian khusus yang diampu seseorang dari pendidikan formal secara penuh diartikan sebagai sebuah profesi. (Wijaya et al., 1991) mengutip gagasan McCully yang menyatakan bahwa pada satu pekerjaan profesional diterapkan langkah-langkah serta cara yang bertumpukan pada pijakan intelektual, yang dengan sengaja dan serius musti bisa dimengerti, serta dengan langsung bisa dipakai untuk kepentingan orang banyak. Pendapat tersebut juga bisa diartikan bahwa seseorang yang memberikan pelayanan sebagai bentuk pengabdian dengan dilandasi kemampuan profesional serta falsafah hidup yang kuat merupakan hakekat dari pekerja profesoal. Dengan demikian guru harus mempunyai pribadi yang kuat sebagai seorang pendidik. 
Profesionalisme guru diartikan juga sebagai tingkat penampilan seseorang dalam melakukan tanggungjawab pekerjaan sebagai guru dengan didukung keterampilan serta kode etik. Eksistensinya guru adalah sebagai pendidik profesional di lembaga sekolah, artinya guru bisa dikatakan sebagaipemberi tauladan yang baik, memiliki jabatan administratif, dan juga sebagai petugas kemasyarakatan. Berdasarkan pengertian di atas dapat disimplkan bawa profesionalisme guru adalah kemampuan seorang guru untuk melaksanakan tanggungawab utamanya sebagai pendidik secara baik, serta harus menguasai kemampuan membuat rencana kerja dan melaksanakan evaluasi pembelajaran dengan baik. Pada dasarnya supervisi seharusnya dilaksanakan secara berkala oleh kepala sekolah kepada setiap guru dalam melaksanakan tugasnya agar kinerjanya bisa di evaluasi dengan baik. Kepala sekolah bisa dibantu oleh wakilnya atau guru senior, apabila jumlah guru cukup banyak dalam melaksanakan supervisi. Keberhasilan kepala sekolah dalam melakukan supervisi dapat dilihat dari kinerja guru yang meningkat, hal ini bisa dilihat dari kesadaran serta keahlian dalam menyelesaikan tugas lebih baik dan bertanggung jawab.

\section{b) Disiplin Kerja Guru}

Handoko dalam (Turangan, 2017) menyatakan kegiatan manajemen untuk menjalankan standarstandar keorganisasian adalah definisi dari disiplin. Disiplin merupakan suatu aktifitas yang dilakukan untuk memberikan motivasi kepada karyawan agar bisa menerapkan standar dan tata tertib yang diberlakkan sehingga dapat mencegah penyelewengan kerja. Disiplin juga diartikan sebagai bentuk pengendalian diri karyawan dalam sebuah tim kerja pada suatu organisasi dan pelaksanaan kerja yang teratur serta menunjukkan 
tingkat kesungguhan yang maksimal. Disiplin kerja mempunyai arti penting bagi perusahaan/lembaga, dengan adanya disiplin kerja pada setiap karyawan maka akan menjadikan sebuah lembaga lebih maju, karena karyawan yang memiliki disiplin dalam melaksanakan pekerjaan akan mampu menyelesaikan tugas yang ada dalam lembaga tersebut, meskipun tidak secara langsung terlihat menghasilkan pekerjaan yang sempurna. Tetapi dalam jangka waktu tertentu seorang karyawan akan mampu lebih baik melaksanakan pekerjaannya. Pengertian disiplin kerja yang dikemukakan oleh Keith Davis yang dikutip (Mangkunegara \& Prabu, 2013) adalah sikap dan tingkah laku guru dalam mematuhi semua pedoman yang ada serta peraturan yang menjadi ketetapan untuk tercapainya tujuan sebuah organisasi. Disiplin berkaitan erat dengan perilaku karyawan dan memiliki pengaruh terhadap kinerja, dalam hal ini guru juga merupakan seorang karyawan.

\section{c) Peningkatan Mutu Pendidikan}

Mutu dalam pendidikan adalah sebuah jasa layanan, dimana fokus utamanya adalah terletak pada peserta didik, sehingga mutu seyogyanya mampu memenuhi kebutuhan dan harapan berbagai pihak. Mutu pendidikan berkembang seiring dengan tuntutan kemajuan ilmu dan teknologi. Sebagai lembaga pendidikan formal, sangat ditekankan kepada sekolah dalam prosesnya harus adanya peningkatan mutu pendidikan yang terprogram dengan baik. Hal ini sebagai jawaban atas kebutuhan dan dinamika masyarakat yang terus berkembang, sehingga peningkatan mutu sumber daya manusia mampu terwujud dengan baik melalui pelaksanaan pendidikan. Karakteristik keseluruhan atas jasa yang ditunjukkan dengan kemampuan dalam memberi kepuasan terhadap kebutuhan yang diminta konsumen adalah pengertian mutu secara umum. Dalam 
ranah pendidikan, pengertian mutu tercakup pada input, proses, dan output pendidikan (Kusnandi, 2018).

Mutu pendidian adalah kemampuan pemanfaatan sumber-sumber pendidikan sebagai upaya meningkatkan kompetensi belajar semaksimal mungkin oleh lembaga pendidikan (Juliantoro, 2017). Sistem Penjaminan Mutu Pendidikan (SPMP) merupakan keseluruhan bagian fungsi manajemen pendidikan, yang mengemban amanat tugas dalam mengevaluasi standar mutu sebagaimana yang telah ditetapkan dalam kebijakan. Fokus keiatan SPMP adalah dalam meningkatan mutu secara terus menerus dengan cara mengevaluasi mutu sistem pendidikan, kinerja lembaga pendidikan, serta mutu program studi. SPMP merupakan alat kebijakan yang dipandang mampu menjadikan efektif implementasi kebijakan dalam meraih akuntanbilitas satuan pendidikan terhadap lingkungan masyarakat luas.

Upaya dalam meningkatkan mutu sebuah sekolah menurut (Danim, 2007) harus melibatkan lima faktor utama yaitu, 1) bagaimana Kepala Sekolah memimpin; 2) siswa sebagai pusat; 3) peran serta guru; 4) kurikulum yang dinamis; 5) jaringan kerjasama yang luas. Kepala Sekolah harus menguasai dan memahami visi dan misi kerja secara jelas, bekerja dengan sungguh-sungguh, motivasi kerja tinggi, ikhlas dalam bekerja, memberikan layanan yang maksimal, serta disiplin kerja yang kuat. Strategi yang biasa diterapkan adalah memposisikan peserta didik sebagai pusat belajar, sehingga kompetensinya dapat digali, dengan demikian sekolah bisa mengetahui potensi peserta didik.

\section{Metode Penelitian}

Metode yang digunakan dalam penelitian ini adalah deskriptif dengan pendekatan kuantitatif. Pada penelitian 
deskriptif berfokus pada pemecahan masalah faktual pada saat penelitian dilakukan (Soendari, n.d.). Penelitian ini dilaksanakan dengan cara survey, sehingga perkiraan dan hubungan antar variabel dapat diukur sekaligus. Sedangkan penggunaan metode kuantitatif dengan maksud untuk memperoleh gambaran pengaruh yang didasarkan atas sifat-sifat masalah yang diteliti. Populasi pada penelitian ini adalah guru SDN 04 Cipedak dan MIN 08 Jagakarsa, Jakarta Selatan berjumlah 61 orang. Sedangkan sampel penelitian dengan jumlah 30 orang guru, dari masingmasing sekolah berjumlah 15 guru dan Instrumen yang digunakan berupa angket pertanyaan.

\section{Hasil Penelitian Dan Pembahasan}

\section{a) Has]il Uji Normalitas}

Penelitian ini menggunakan uji Kolmogorov-smirnov untuk uji normalitas, dengan kriteria signifikansi untuk uji satu sisi hasil perhitungan harus lebih besar dari >0,05 berarti berdistribusi normal. Hasil uji normalitas profesionalisme guru diperoleh nilai $\rho=1,68$ atau $\rho>0,05$, maka $\mathrm{H} 0$ diterima dan $\mathrm{H} 1$ di tolak, artinya data profesionalisme guru berasal dari populasi berdistribusi normal. Hasil uji normalitas disiplin kerja guru diperoleh nilai $\rho=1,38$ atau $\rho>0,05$, maka H0 diterima dan $\mathrm{H} 1$ di tolak, ini berarti data disiplin kerja guru berasal dari populasi berdistribusi normal. Hasil uji normalitas mutu pendidikan diperoleh nilai $\rho=1,81$ atau $\rho>$ 0,05, maka H0 diterima dan H1 di tolak, hal ini menunjukkan bahwa data mutu pendidikan berasal dari populasi dengan distribusi normal.

\section{b) Hasil Uji Linieritas}

Hasil uji linieritas menunjukkan hubungan antara profesionalisme guru terhadap mutu pendidikan diperoleh nilai $F=3,96$ dengan nilai probabilitas (Kolom Sig) $\rho$ 
$=0,53$. Karena nilai Signifikansi $\rho=0,53>0,05$ dengan demikian disimpulkan $\mathrm{H} 0$ diterima dan $\mathrm{H} 1$ ditolak serta model regresinya bersifat linear. Sedangkan untuk hasil hubungan antara disiplin kerja guru dan mutu pendidikan diperoleh nilai $\mathrm{F}=5,23$ dengan nilai probabilitas (Kolom Sig) $\rho=0,561$. Karena nilai Signifikansi $\rho=0,561>0,05$ dengan demikian diperoleh kesimpulan $\mathrm{HO}$ diterima dan H1 ditolak serta model regresinya bersifat linear.

\section{c) Hasil Uji Multikolinieritas}

Model regresi disebut bebas dari multikolinieritas apabila memiliki nilai VIF (Variance Inflation Faktor) di sekitar angka 1 dan angka tolenrance mendekati angka 1. Berdasarkan hasil uji multikolinieritas dengan nilai Tolerance 0,88 hasil ini masih dibawah angka 1 dan angka VIF melebihi angka 1, maka t adanya dugaan terdapat multikolinieritas antara variabel profesionalisme guru dan disiplin kerja guru terhadap variabel mutu pendidikan.

\section{d) Hasil Uji Hipotesis}

Hasil uji hipotesis pertama menunjukkan nilai sebesar 0,88 untuk koefisien korelasi (r) antara profesionalisme guru terhadap mutu pendidikan, yang berarti bahwa pengaruh antara profesionalisme guru terhadap mutu pendidikan dapat dijelaskan sebesar 78,5\% selebihnya sebesar 21,5\% dipengaruhi oleh faktor yang lainnya. Koefisien determinasi (r2 x 100) sebesar $0,88 \times 100=0,78$ atau 78,5\%, hal ini menunjukan bahwa pengaruh berdasarkan varians hubungan profesionalisme guru dengan mutu pendidikan dapat dijelaskan sebesar 78,5\% sebagai pengaruh murni, selebihnya sebesar 21,5\% dipengaruhi oleh faktor lain yang tidak di amati oleh penulis. Berdasarkan hasil tersebut, dapat disimpulkan bahwa pengaruh profesionalisme guru terhadap mutu pendidikan adalah signifikan pada $\alpha=0,05$. 
Berdasarkan hasil uji hipotesis kedua terdapat pengaruh positif dan signifikan antara disiplin kerja guru terhadap mutu pendidikan di kedua sekolah, ditemukan Fhitung sebesar 33,01. Nilai Fhitung sebesar 33,00 > Fhitung (29) pada $\alpha=0,05=3,34$ maka dapat disimpulkan secara generalisasi pengaruh antara disiplin kerja guru terhadap mutu pendidikan adalah signifikan. Dari hasil analisis tersebut diperoleh besaran koefisien korelasi antara disiplin kerja guru terhadap mutu pendidikan adalah 0,91 selebihnya dipengaruhi oleh faktor yang lainnya. Koefisien determinasi ( $\mathrm{r} 2$ x 100) sebesar 0,912 x $100=0,83$ atau $83,5 \%$, hal ini menunjukan bahwa berdasarkan varians pengaruh disiplin kerja guru terhadap mutu pendidikan dapat dijelaskan sebesar 83,5\%. Hal ini menunjukan bahwa pengaruh berdasarkan varians pengaruh disiplin kerja guru terhadap mutu pendidikan dapat mempengaruhi sebesar 83,5\% pengaruh murni dan sisanya dipengaruhi oleh hal lain. sehingga dapat diambil kesimpulan bahwa pengaruh antara disiplin kerja guru terhadap mutu pendidikan signifikan pada taraf signifikan 0,5\%.

Berdasarkan hasil uji signifikan regresi berganda bahwa secara bersama-sama kedua variabel tersebut baik profesionalisme guru maupun disiplin kerja guru terhadap mutu pendidikan terdapat pengaruh positif dan signifikan. Pengaruh antara profesionalisme guru dan disiplin kerja guru secara bersama-sama terhadap mutu pendidikan ditunnjukan oleh koefisien korelasi berganda (Ry12) sebesar 0,89. Analisis regresi linear berganda variabel profesionalisme guru dan disiplin kerja guru terhadap mutu pendidikan menghasilkan persamaan regresi seperti berikut ini : Y = 8,18+0.56 X1 +0,72 X2. Berdasarkan hasil uji hipotesis, menunjukann bahwa secara bersamasama dapat dibuktikan antara variabel profesionalisme guru dan disiplin kerja guru terhadap mutu pendidikan 
secara simultan ada pengaruh signifikan diperoleh nilai Fhitung sebesar 17,24 dimana > Ftabel (29) sebesar 3,33 dengan tingkat signifikan sebesar 0,00 karena 0,00<0,05, maka dapat dikatakan profesionalisme guru dan disiplin kerja guru secara bersama-sama atau simultan ada pengaruh terhadap mutu pendidikan. Hasil pengujian ini mengandung makna bahwa baik profesionalisme guru dan disiplin kerja guru dapat meningkatkan mutu pendidikan dengan signifikan.

\section{e) Pengaruh Profesionalisme Guru Terhadap Peningkatan Mutu Pendidikan}

Berdasarkan pada hasil analisis data di interpretasikan antara profesionalisme guru terhadap mutu pendidikan baik secara sendiri maupun secara bersama terdapat pengaruh signifikan, akan tetapi belum menunjukkan berapa besar pengaruhnya, maka besaran pengaruh tersebut dihitung dengan cara manual dengan rumus koefisien determinasi: r2 x 100\%, dimana hasil analisis koefisien korelasi sebesar 0,886. Hasil perhitungan selanjutnya adalah : r2 x 100\% = 0,8862 $\mathrm{x}$ $100 \%=0,785 \times 100 \%=78,5 \%$. Sehingga dapat dinyatakan bahwa profesionalisme guru memiliki pengaruh sebesar $78,5 \%$ terhadap mutu pendidikan dan sisanya 21,5\% disebabkan oleh faktor lainnya yang tidak penulis amati. Sejalan dengan pernyatan (Sari, 2013) yang menyatakan keberadaan tenaga pendidik yang profesional adalah suatu hal yang harus, karena mereka akan mampu melakukan tanggungjawab kerjanya secara profesional pula sehingga menghasilkan pendidikan dan lulusan yang lebih bermutu.

\section{f) Pengaruh Disiplin Kerja Guru Terhadap Peningkatan Mutu Pendidikan}

Hasil disiplin kerja guru dengan mutu pendidikan belum menunjukkan berapa besar pengaruhnya, maka 
besarnya pengaruh dihitung dengan cara manual memakai rumus koefisien determinasi berikut : $r 2 \times 100 \%$. Dimana r merupakan nilai hasil analisis koefisien korelasi sebesar 0,91 . Hasil perhitungan selanjutnya adalah : $\mathrm{KD}=\mathrm{r} 2 \mathrm{x}$ $100 \%=0,912 \times 100 \%=0,83 \times 100 \%=83,5 \%$. Dengan hasil tersebut dapat dinyatakan bahwa disiplin kerja guru terhadap mutu pendidikan memiliki pengaruh sebesar $83,5 \%$ dan sisanya sebesar $16,5 \%$ disebabkan oleh faktor lain yang tidak diamati penulis. Disiplin kerja memiliki peran yang kuat dalam meningkatkan mutu pendidikan, hal ini sesuai dengan Danim dalam (Rahmat Syaifullah 2012), yang menyatakan bahwa jika hendak meningkatkan mutu pendidikannya maka sebuah institusi sedikitnya harus melibatkan lima faktor dominan antara lain Kepala Sekolah dan guru yang memilki disiplin yang kuat.

\section{g) Pengaruh Profesionalisme dan Disiplin Kerja Guru Terhadap Peningkatan Mutu Pendidikan}

Secara simultan hasil analisis data di interpretasikan antara variabel profesionalisme guru dan disiplin kerja guru terhadap mutu pendidikan secara simultan terdapat pengaruh signifikan. Hasil analisisnya menghasilkan nilai $\mathrm{R}$ sebesar 0,89 sedangkan nilai $\mathrm{R}$ Square sebesar 0,79 atau 79,9\%, hal ini dapat dinyatakan dengan hasil analisa secara bersama profesionalisme guru dan disiplin kerja guru terhadap mutu pendidikan memiliki nilai positif, dan tingkat pengaruhnya sangat kuat. Sejalan dengan hasil penelitian (Muhammad, 2016), yang menyatakan bahwa ada empat aspek kompetensi yang mampu meningkatkan mutu pendidikan di SDN 65 Katteong Kab. Pinrang yaitu, pedagogik, kepribadian, sosial, dan kompetensi profesional.

Berdasarkan hasil uji hipotesis menunjukkan bahwa pengaruh antara profesionalisme guru dan disiplin kerja guru dapat meningkatkan mutu pendidikan, 
baik dengan cara sendiri maupun secara bersama, membuktikan adanya pengaruh positif dan signifikan antara profesionalisme guru dan disiplin kerja guru terhadap variabel mutu pendidikan.

\section{Simpulan}

Berdasarkan dari data yang diperoleh penelitian ini dapat disimpulkan sebagai berikut, 1) Adanya pengaruh positif antara profesionalisme guru terhadap peningkatan mutu pendidikan. Berdasarkan hasil ini maka hendaknya terus membenahi profesionalisme guru agar dimasa mendatang akan lebih baik dan dapat meningkatkan mutu pendidikan lebih optimal lagi sesuai dengan yang diharapkan pimpinan maupun seluruh orang tua siswa. 2) Adanya pengaruh positif antara disiplin kerja guru terhadap peningkatan mutu pendidikan. Dengan hasil demikian pimpinan harus berupaya dapat mempertahankan bila perlu terus meningkatkan disiplin kerja guru lebih baik lagi agar kedepannya mutu pendidikan dapat ditingkatkan sesuai harapan banyak pihak. 3) Secara bersama antara profesionalisme guru dan disipilin kerja guru memiliki pengaruh signifikan terhadap peningkatan mutu pendidikan di guru SDN 04 Cipedak dan MIN 08 Jagakarsa, Jakarta Selatan. Sehingga profesionalisme dan disiplin kerja seyogyanya harus dimiliki secara baik oleh semua guru, jika mutu pendidikan ingin menjadi lebih baik. Peningkatan sumberdaya manusia khususnya guru selaku insan pendidik agar lebih kompeten dalam profesinya dapat dilakukan dengan mengikuti berbagai pelatihan yan diselenggarakan sekolah sendiri maupun pihak luar. 


\section{DAFTAR PUSTAKA}

Armani, A. R., \& Margunani, (2017). Economic Education Analysis Journal PENGARUH PROFESIONALISME GURU, DISIPLIN KERJA DAN LINGKUNGAN KERJA TERHADAP KINERJA GURU MATA PELAJARAN EKONOMI DI SMA NEGERI SEKABUPATEN SRAGEN Info Artikel. In EEAJ (Vol. 6, Issue 1).

Danim, S. (2007). Dari unit Birokrasi ke Lembaga Akademik. Jakarta: PT Bumi Aksara.

Darmadi, H. (2015). MENJADI GURU PROFESIONAL diperbincangkan, karena guru merupakan sumber kunci keberhasilan pendidikan . didik yang menyangkut berbagai aspek yang bersifat manusiawi yang unik dalam. Jurnal Edukasi, 13(2), 161-174.

Dewi, T. A. (2015). PENGARUH PROFESIONALISME GURU DAN MOTIVASI KERJA TERHADAP KINERJA GURU EKONOMI SMA SE-KOTA MALANG (Vol. 3, Issue 1).

Haryati, T. (n.d.). PENGARUH PROFESIONALISME GURU, MOTIVASI DAN KEDISIPLINAN KERJA TERHADAP KONERJA GURU HONORER SEJARAH DI SMA SE-KABUPATEN BIMA.

Juliantoro, M. (2017). Peran Kepala Sekolah dalam Meningkatkan Mutu Pendidikan. Al-Hikmah: Jurnal Kependidikan Dan Syariah, 5(2), 24-38.

Kunandar, S. P., \& Si, M. (2010). Guru profesional implementasi kurikulum satuan pendidikan (KTSP) dan sukses dalam sertifikasi Guru. Penerbit PT. Raja Grafindo Persada: Jakarta.

Kusnandi. (2018). Konsep Dasar dan Strategi Penjaminan Mutu Pendidikan: Sebagai Review Kebijakan Mutu Pendidikan. Indonesian Journal of Education Management \& Administration Review, 2(1), 193-204. https://doi. org/10.4321/IJEMAR.V2I1.1824. 
Mangkunegara, A. A., \& Prabu, A. (2013). Sumber Daya Manusia Perusahaan, Cetakan Kesebelas. Bandung: Remaja Rosdakarya.

Muhammad, Y. (2016). PROFESIONALISME GURU DALAM PENINGKATAN MUTU PENDIDIKAN. In LENTERA PENDIDIKAN (Vol. 19, Issue 1).

Mulatsih, H., Ayu Nyoman, N. M., Egar, N., \& di Kabupaten Kendal, G. (2018). PENGARUH GAYA KEPEMIMPINAN DEMOKRATIS KEPALA PAUD DAN PROFESIONALISME GURU TERHADAP MUTU PAUD DI KECAMATAN GEMUH KABUPATEN KENDAL. In JMP Universitas PGRI Semarang (Vol. 7).

RAHMAT SYAIFULLAH, A. (2012). Penerapan Model Pembelajaran PBI (Problem Based Instruction) dalam Upaya Peningkatan Prestasi Belajar Siswa Kelas XSMK PGRI Sukodadi Lamongan. Jurnal Pendidikan Teknik Mesin, 1(01), 1-8.

Sari, C. D. L. (2013). Pengaruh Profesionalisme Guru dan Motivaso Kerja Terhadap Kinerja Guru SMA Batik 2 Surakarta.

Soendari, T. (n.d.). Metode Penelitian Deskriptif.

Turangan, J. K. (2017). Pengaruh Kompetensi, Disiplin Kerja Dan Profesionalisme Terhadap Kinerja Guru Di SMA Negeri 1 Manado. Jurnal EMBA: Jurnal Riset Ekonomi, Manajemen, Bisnis Dan Akuntansi, 5(2).

Wijaya, C., Djadjuri, D., \& Rusyan, A. T. (1991). Upaya pembaharuan dalam pendidikan dan pengajaran. PT Remaja Rosdakarya.

Zubaidah, S. (2015). Pengaruh budaya sekolah dan motivasi kerja guru terhadap mutu pendidikan di SMK N 1 Pabelan. Prosiding Seminar Nasional Pendidikan "Meretas Sukses Publikasi Ilmiah Bidang Pendidikan Jurnal Bereputasi," November, 177-184. 